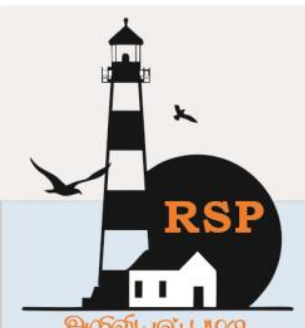

INTERNATIONAL RESEARCH JOURNAL ON ADVANCED SCIENCE HUB

ISSN : $2582-4376$
Open Access

RSP SCIENCE HUB

(The Hub of Research Ideas)

Available online at www.rspsciencehub.com

\title{
Experimental Investigation on Banana Fiber Reinforced Phenol Formaldehyde Composite for Automotive Application
}

\section{G Subbiah Jeeva ${ }^{1}$, S Prem Kennedy ${ }^{2}$, S.Nishanth ${ }^{3}$ P Shanjai ${ }^{4}$ V Ajith Tisho ${ }^{5}$}

${ }^{1}$ Assistant Professor, Department of Mechanical Engineering, Loyola Institute of Technology and science-

Thovalai

2, 3, 4,5 UG, Student Department of Mechanical Engineering, Loyola Institute of Technology And science-

Thovalai.

premkennedy4@gmail.com ${ }^{2}$

\begin{abstract}
Increasing environmental awareness throughout the world has greatly impacted materials engineering and design. Renewed interest in the utilization of natural materials addresses ecological issues such as recyclability and environmental safety. Currently synthetic fibers like glass, carbon and aramids are widely being used in polymer-based composite because of their high stiffness and strength; However the fibers have serious draw-backs in terms of their bio degradability, initial processing cost, recyclability, energy consumption, machine abrasion, health hazards, etc. Despite these, most significantly, adverse environmental impacts alter the attention from synthetic fibers to natural/renewable fibers. The introduction of natural fibers from annually renewable sources is now popularly used as reinforcement in polymer matrix. The use of banana based natural fiber composite plays important role, due its vast advantage over synthetic fiber. Hence this project would be based on using banana fiber reinforced phenol formaldehyde composite, and testing its application for automobile.
\end{abstract}

Keywords: banana fiber - phenol formaldehyde- recyclability-environmental safety- application for automobile

\section{Introduction}

The growing global concern over the environment is now encouraging the use of renewable sources of materials that do not harm nature and come from an alternative source of good economic potential. Lignocelluloses' fibers fall into this category, since they originate from renewable resources, are biodegradable and recyclable [1], and in tropical countries these fibers can be produced in abundance, facilitating their use. In recent years, lignocelluloses' fibers including banana, sisal, jute and coconut fibers have attracted the attention of many research groups that are considering their use for industrial purposes and the reinforcement of polymers. These fibers have many advantages compared to glass fibers, such as low density and low cost, and they are recyclable and biodegradable [2-5].

\section{Literature review}

\subsection{Autar K.Kaw}


www.rspsciencehub.com

In his text named as "Mechanics of Composite Materials", he explained the Basics of composites Materials.

\subsection{Michael W.Hyer}

In his text book named as "Stress analysis of Fiber-Reinforced Composite Materials", he relies to a large degree on a materials science view point to describe fibers, matrix materials, and the fiber sizing.

\section{Experimental Methodology}

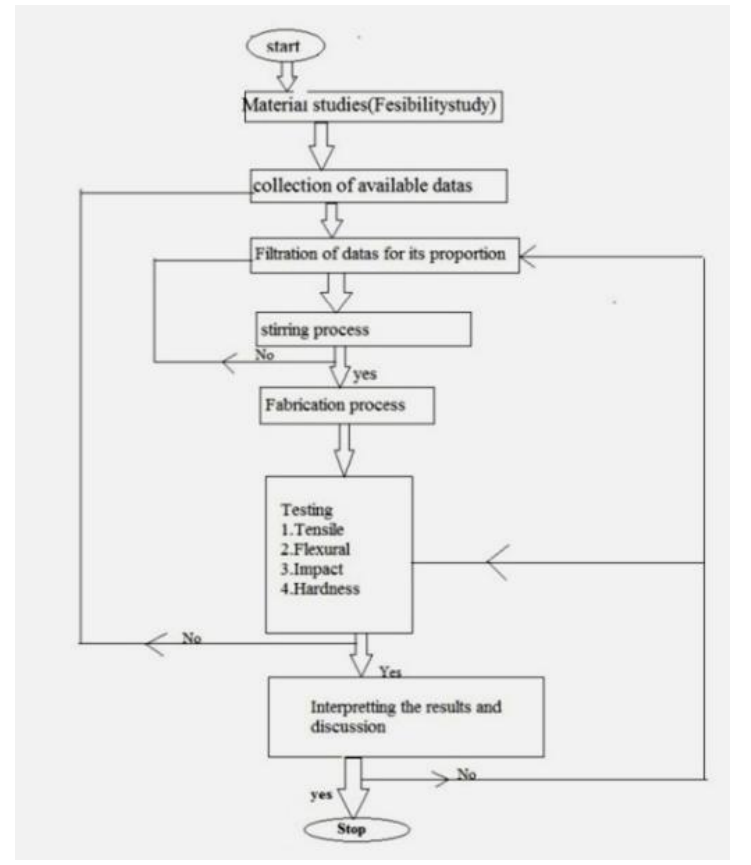

Fig.1.Experimental Methodology

The methods which denote for the making of composite material is stirring method which it stirs banana fibre and phenol formaldehyde but the testing machine is important to notice it because tests are to be carried in NIT, Trichy. The test we done is tensile, flexural, impact and hardness. The machines are INSTRON universal testing machine, three point flexural test machine with the utilization of INSTRON, izod impact machine and Vickers hardness test machine for checking the material hardness and these are discussed in this chapter and also we present the pictorial representation of work flow methodology as shown in fig. 1

\section{Results \& Discussion}

After, the collection of data and estimated
Volume 02 Issue 08 August 2020

collection of banana fiber and phenol formaldehyde proportions, an experimental process is to be carry out with the help of (1).BFPF can be test by many mechanical methods but the most popular methods are Tensile test, Impact test, Flexural test etc., and the BFPF is fabricated in NIT trichy, and it is shown in Fig.2. Proportions of banana fiber and phenol formaldehyde showing the strength composition and elastic property changes in certain times and its influence of fiber parameter changes are also identified and classified in this forthcoming chapter and the tested results are shown with respect to corresponding values.

\subsection{Banana Fiber and Phenol- Formaldehyde Resin Proportions by Weight.}

BFPFC1 Fiber length (5 mm) $(10 \mathrm{wt} \%)+$ pf $(90 \mathrm{wt} \%)$

BFPFC2 Fiber length $(5 \mathrm{~mm})(15 \mathrm{wt} \%)+\mathrm{pf}(85 \mathrm{wt} \%)$

BFPFC3 Fiber length $(5 \mathrm{~mm})(20 \mathrm{wt} \%)+$ pf $(80 \mathrm{wt} \%)$

BFPFC4 Fiber length $(10 \mathrm{~mm})(10 \mathrm{wt} \%)+\mathrm{pf}(90 \mathrm{wt} \%)$

BFPFC5 Fiber length $(10 \mathrm{~mm})(15 \mathrm{wt} \%)+\mathrm{pf}(85 \mathrm{wt} \%)$

BFPFC6 Fiber length $(10 \mathrm{~mm})(20 \mathrm{wt} \%)+\mathrm{pf}(80 \mathrm{wt} \%)$

BFPFC7 Fiber length (15 mm) $(10 \mathrm{wt} \%)+$ pf $(90 \mathrm{wt} \%)$

BFPFC8 Fiber length (15 mm) (15 wt\%) + pf (85 wt $\%)$

BFPFC9 Fiber length $(15 \mathrm{~mm})(20 \mathrm{wt} \%)+\mathrm{pf}(80 \mathrm{wt} \%)$

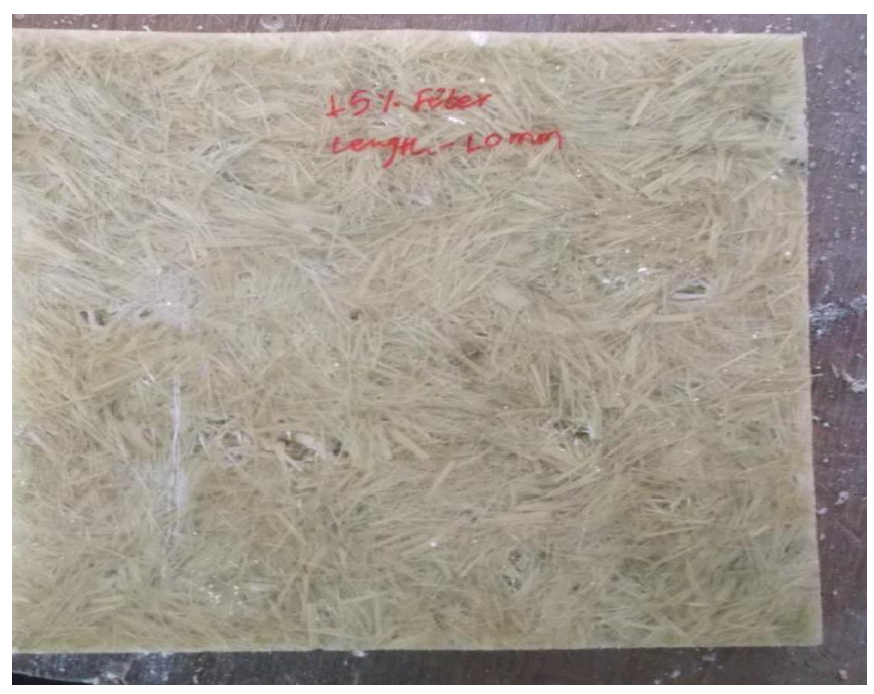

Fig.2 Fabricated short banana fiber reinforced PF composites

4.2 Tensile Strength Test 
www.rspsciencehub.com

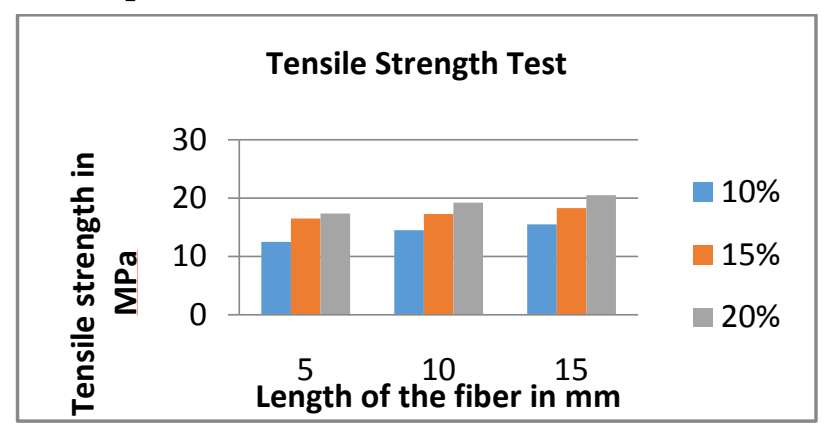

Fig.3.Tensile Strength Test Result

\subsubsection{Test Result on Tensile Strength}

The tensile test source that if we are increasing the fibre length and loading means the tensile strength will be increased. We can see this by the above Figure (graph).

\subsection{Flexural Strength Test}

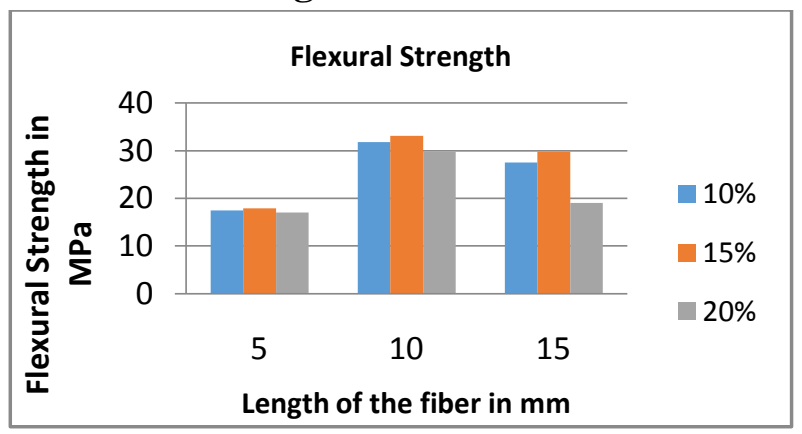

Fig.4.Flexural Strength Test result

\subsubsection{Test Result on Flexural Strength}

The flexural strength on the set of composite material shown in Figure (graph). The graph shown that when fiber length increases the flexural strength of the fabricated composites first increases up to $10 \mathrm{~mm}$ length and then decreases. When fiber loading increase then flexural strength increase up to fiber loading $15 \%$ then decreases. We got maximum flexural strength is observed when fiber length is $10 \mathrm{~mm}$ and loading is $15 \%$.

\subsection{Impact Strength Test}

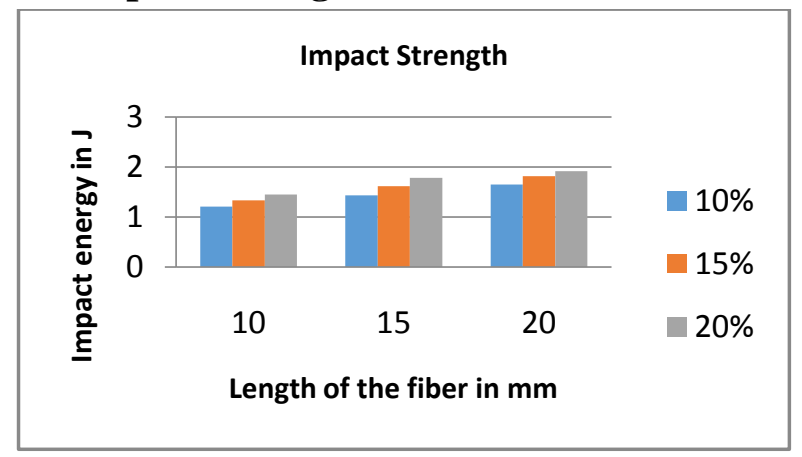

Fig.5.Impact Strength Test Result
Volume 02 Issue 08 August 2020

\subsubsection{Test Result on Impact Strength}

The impact test source that if we are increasing the fibre length and loading means the impact strength also will be increased. We can see this by the above Figure (graph). From the graph we can know. The maximum impact energy absorbed by the material fiber length of $15 \mathrm{~mm}$ and $20 \%$ fiber content.

\subsection{Hardness Test}

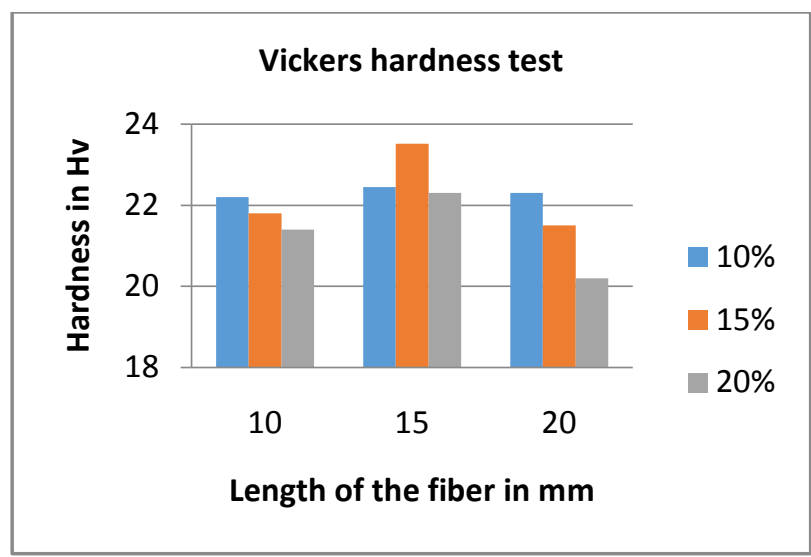

Fig.6.Hardness Test Result

\subsection{Test Result on Hardness}

The tensile test source that if we are increasing the fibre length and loading means the tensile strength will be increased. We can see this by the above Figure (graph).

The Figure (graph) shows the hardness of the set of composite materials. From this graph we can understand the hardness value increases with increase in fiber length and it is maximum at 10 $\mathrm{mm}$ fiber length. We got maximum hardness observed by the material fiber length of $15 \mathrm{~mm}$ and $15 \%$ fiber content.

\subsection{Test Conclusion}

- The banana fiber based PhenolFormaldehyde composites with different loading of fiber and different lengths of fiber fabricated by string process.

- The mechanical properties of the composites like as hardness, tensile strength, flexural strength and impact 
www.rspsciencehub.com

strength are taken. It has been shows that the better mechanical properties found for composites reinforced with10 $\mathbf{~ m m}$ fiber length with $\mathbf{1 5 \%}$ fiber loading.

4.8 Tests \& Results in Composite Made By Woven Roving Banana Fiber

4.8.1 Water Absorption Test at room temperature

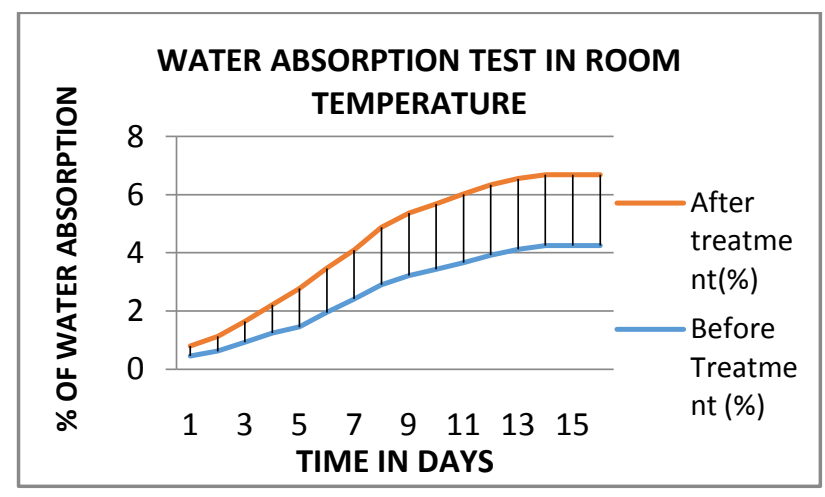

Fig.7.Water Absorption Test Report at room temperature

\subsubsection{Water Absorption Test in boiling water}

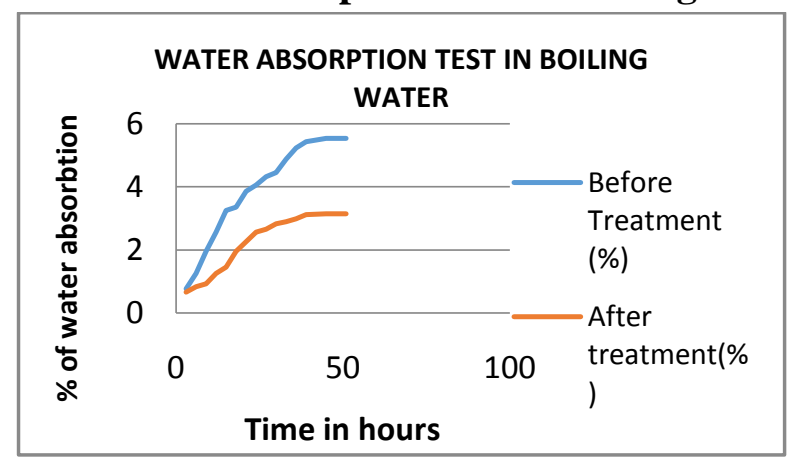

Fig.8.Water Absorption Test Report in boiling water

The water absorption of composites are shown in Figure (graph). It can be understood from the figure that the water absorption decreases after treatment.

\subsection{Tensile Test Result}

The tensile strength of neat resin, untreated composites and treated composite are shown in Figure (graph). We can be understand from the figure that the tensile strength increases in the woven roving model and the tensile also increased after treatment.
Volume 02 Issue 08 August 2020

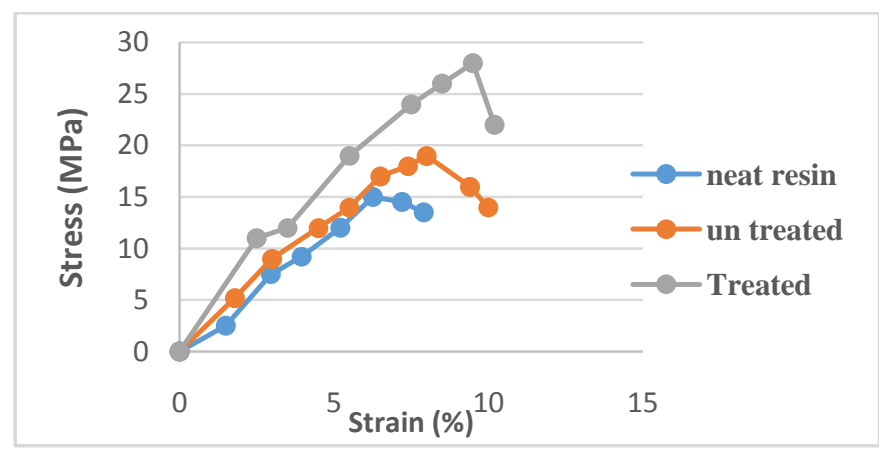

Fig.9.Tensile Test Result after woven roving

The tensile strength of composites are shown in Figure (graph). It can be understood from the figure that the tensile strength increases in the woven roving model and the tensile also increased after treatment.

\subsection{Flexural Strength Test Result}

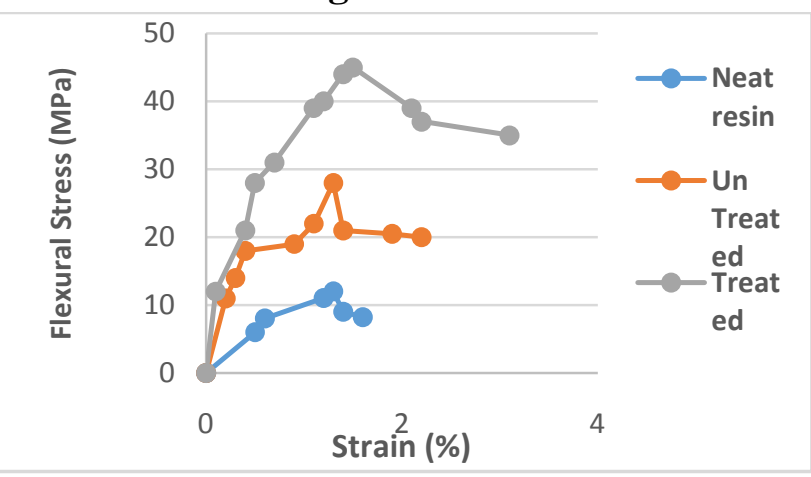

Fig.10. Flexural Strength Test Result after woven roving

The Flexural Strength of composites shown in Figure (graph). It can be understood from the figure that the Flexural Strength increase in the woven roving model and the tensile also increased after treatment.

\subsection{Impact Strength Result}

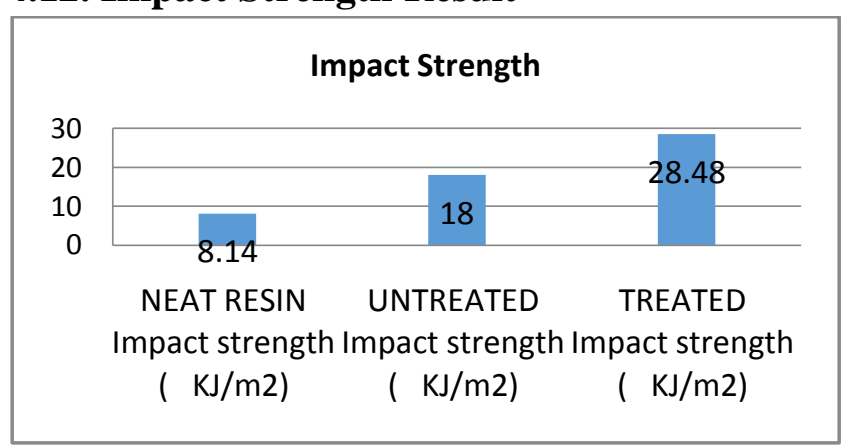

Fig.11.Impact test result.

The Impact Strength of composites shown in Figure (graph). It can be understood from the figure that the Impact Strength increases in the woven roving model and the tensile also increased after treatment. 
www.rspsciencehub.com

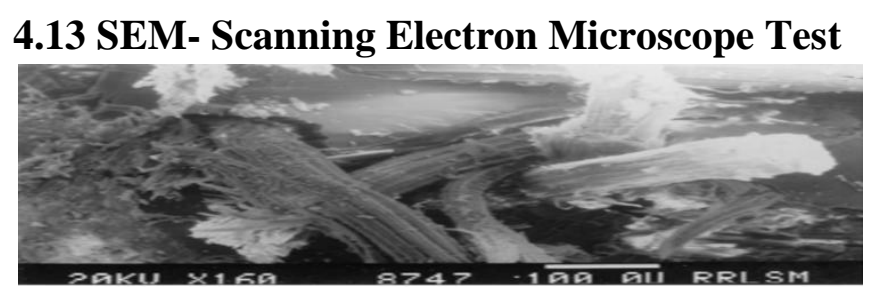

Fig.12.Non treated-SEM image without fiber pull

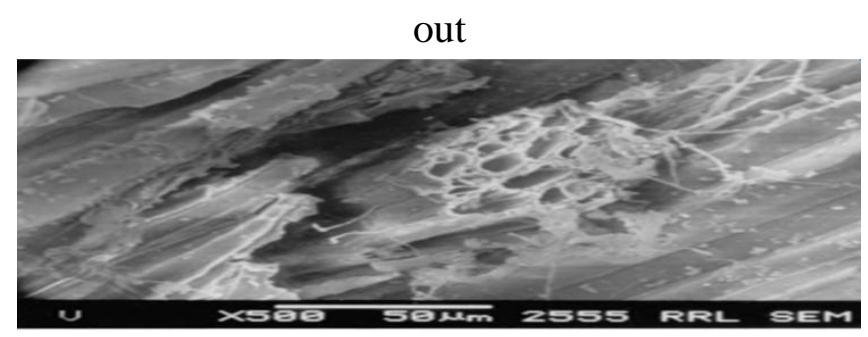

Fig.13 Non treated- Fiber SEM image with fiber/matrix pull out

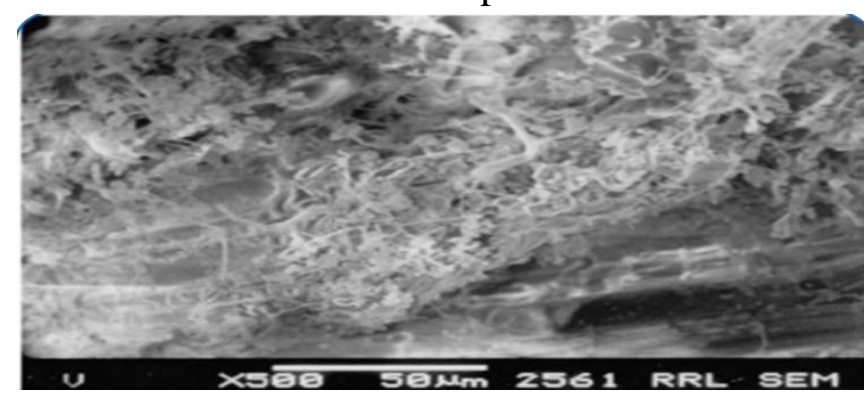

Fig.14.Treated fiber- SEM image with good interfacial adhesion

The SEM tests of composites are shown in Fig.12, 13\&14It can be understood from the figure that the good fiber matrix adhesion provides after treatment.

\subsection{Comparative Result $[18,19]$}

\begin{tabular}{|c|c|c|c|}
\hline Items & $\begin{array}{c}\text { Tensile } \\
\text { strength } \\
\text { (Mpa) }\end{array}$ & $\begin{array}{c}\text { Flexural } \\
\text { strength } \\
\text { (Mpa) }\end{array}$ & $\begin{array}{c}\text { Impact } \\
\text { strength } \\
\text { KJ/m2 }\end{array}$ \\
\hline Banana Fiber/Polyester & 23.98 & 43.38 & \\
\hline banana Fiber/Epoxy & 22.63 & 41.28 & \\
\hline $\begin{array}{c}\text { Banana Fiber/Plastic } \\
\text { polymer }\end{array}$ & 24.56 & 38 & \\
\hline Pine appleLeaf/polyester & 22.9 & 80.2 & \\
\hline Banana fiber/Vinyl ester & 17.65 & 48.2 & \\
\hline Jute \& Hemp/Epoxy & 22.46 & 37.59 & 1.33 \\
\hline jute \& HempI/polyester & 25.95 & 42.18 & 2.84 \\
\hline $\begin{array}{c}\text { Banana fiber/Phenol } \\
\text { formaldehyde }\end{array}$ & 28 & 45 & 28.48 \\
\hline
\end{tabular}

\section{Conclusion}

This experimental examination of
Volume 02 Issue 08 August 2020

mechanical behavior of banana fiber based phenol formaldehyde composites are experimental investigated and major conclusions are on follows.

* Fabrication and testing of composite are completed.

* It is proved that the strength is improved as the composite when compared with other composite materials.

* This composite is suitable for making automotive application like bumper. Impact strength of our composite is $28.48 \mathrm{KJ} / \mathrm{m}^{2}$ which is better than steel bumper.

* This composite may be used for Glove Box , Door Panels , Seat Coverings, Seat Surface/Backrest, Floor Panels Flax mat.

\section{Acknowledgement}

We take the privilege to express our sincere gratitude to our beloved parents who were with us extending their support all through the project work.

We wish to thank our management and extend our gratitude and heart-felt thanks to our Chairman, Dr. M.T. Nicholas, M.S., Ph.D., for extending all facilities.

We extend our gratitude and thanks to our principal Dr. J.D. Darwin, M.E., Ph.D., for helping us in our project .Also we thank Dr.M.Shunmuga Priyan,ME.,Ph.D.,M.I.E.,MISTE., Head of our Department for helping me through out the project.

We express our sincere gratitude to Mr. Guru of NIT ,Trichy, for his valuable guidance and sopport provided for our project. 


\section{References}

[1].Sadasivam S, Manickam A (1996) In:

Biochemical Methods 2nd edition. (Eds.)

New Age International (P) Limited Publishers, New Delhi, 13-19.

[2]. Thimmaiah SK (1999) In: Standard methods of Biochemical analysis. (Eds.) Kalyani Publishers, New Delhi, 287-310.

[3].Kiruthika AV, Veluraja K (2009) Experimental Studies on the Physicochemical Properties of Banana Fibre from Various Varieties. Fibers and Polymers 10: 193-199.

[4].Salam, M.A.(2006) Effect of hydrogen peroxide bleaching onto sulfonated jute fiber. J. Appl. Polym. Sci.-, 99, 3603-3607.

[5].Rosa, M.F.; Chiou, B.S.; Medeiros, E.S.; Wood, D.F.; Williams, T.G.; Mattoso, L.H.C.; Orts, W.J.; Iman, S.H.(2009) Effect of fiber treatments on tensile and thermal properties of starch/ethylene vinyl alcohol copolymers/coir biocomposites. Bioresour. Technol.,- 100, 5196-5202. 